\title{
The Modeling of the Grain Growth in a Continuous Reheating Process of a Low Carbon Si-Mn Bearing TRIP Steel
}

\author{
S. JIAO, J. PENNING, ${ }^{1)}$ F. LEYSEN, ${ }^{1)}$ Y. HOUBAERT ${ }^{11}$ and E. AERNOUDT ${ }^{21}$ \\ Formerly at Laboratory for Iron and Steelmaking, Ghent University, now at McGill Metals Processing Centre, M.H. Wong \\ Building, 3610 University Street, Montreal, OC, H3A 2B2 Canada. 1) Laboratory for Iron and Steelmaking, Ghent \\ University, Technologiepark 9, B-9052 Zwijnaarde (Gent) Belgium. 2) Department of Metallurgy and Materials \\ Engineering, Catholic University of Leuven, de Croylaan 2, B-3001 Heverlee (Leuven) Belgium.
}

(Received on May 2, 2000; accepted in final form on June 16, 2000)

\begin{abstract}
Making use of Anelli's idea and an own model for isothermal grain growth, a new model for the grain growth during a continuous reheating process was deduced. This model makes use of the real three dimensional grain diameter instead of the mean linear intercept distance as a measure for the grain size. Two series of experiments have been undertaken: in the first series, the validity of the model for several intermediate temperatures has been investigated, while in the second series, the influence of the heating rate on the validity of the model has been verified. In both cases a quite reasonable matching between the prediction of the model and the experimentally determined three dimensional grain size has been found.
\end{abstract}

KEY WORDS: modeling; austenite grain size; continuous reheating process; TRIP steel.

\section{Introduction}

The initiative for the modelling of a thermomechanical process on a material mainly arises from the following two considerations:

i. a more precise control of the production process.

ii. lowering the costs for the development of new production techniques or the improvement of existing ones.

With these ideas in mind, much research work $^{1-4)}$ has been undertaken to develop an integrated model which can predict the microstructural evolution and the mechanical properties of a product during and after hot rolling. Generally speaking, a global model for the hot rolling process of a steel plate consists of the following partial models:

i. a model for the prediction of the austenite grain growth during the reheating process prior to hot rolling.

ii. a model for the prediction of the flow stress during the hot rolling process.

iii. a model for the prediction of the evolution of the microstructure during hot rolling and on the run out table.

iv. a model for the prediction of the microstructure of steels after coiling.

v. a model for the prediction of the mechanical properties of the final product.

The model for the prediction of the grain growth of steel during the slab reheating process is the first step to a global model. It not only provides the initial data for the prediction of the evolution of the microstructure of a steel during the hot rolling process but it also delivers a contribution to the optimisation of the reheating process.

The construction of this model can be subdivided into two stages:

i. a model for the isothermal grain growth.

ii. the prediction of the grain growth in a continuous reheating process.

The model developed in this paper is based on general principles and can be applied to any steel. In this paper, the model will be applied on a low carbon, $\mathrm{Si}-\mathrm{Mn}$ TRIP steel.

This type of steel was selected since it is very promising for many applications such as the production of car body parts, due to its unique combination of a high tensile strength and uniform elongation. This combination of mechanical properties is provoked by the presence of a mixed ferritic-bainitic-austenitic matrix. However the processing of a TRIP steel needs a strict control of the processing parameters in order to achieve the correct microstructure. Therefore the availability of a predictive model is of great technical importance.

The development of a model for the grain growth during a continuous reheating process requires a model for the isothermal grain growth. So, starting from existing descriptions, an improved model for isothermal grain growth in TRIP steels has been developed and described elsewhere. ${ }^{5,6)}$

\section{Theoretical Background}

\subsection{The Model for Isothermal Grain Growth}

Previous research work has led to the development of the following model for the isothermal soaking of a low carbon, Si-Mn TRIP steel. It relates the real (three dimensional) austenitic grain diameter $d$ to the soaking time $t$ and the absolute soaking temperature $T$ by the following equation: 


$$
d^{n}=d_{0}^{n}+K_{1} \cdot t \cdot \exp \left(K_{2} / T\right)
$$

The values of the coefficients $K_{1}, K_{2}$ and $n$ strongly depend upon the soaking temperature adopted. For a low carbon $\mathrm{Si}-\mathrm{Mn}$ bearing TRIP steel, the following values ${ }^{5,6)}$ have been calculated:

i. when the soaking temperature is lower than $1150^{\circ} \mathrm{C}$ :

$$
\begin{gathered}
\log n=0.531+\frac{307.404}{T} \\
K_{1}=8.74 \times 10^{4} \ldots \ldots \\
K_{2}=4.264 \times 10^{3} \ldots \ldots
\end{gathered}
$$

ii. when the soaking temperature is in the range 1150$1250^{\circ} \mathrm{C}$ :

$$
\begin{gathered}
\log n=-5.214+\frac{8406}{T} \\
K_{1}=1.29 \times 10^{-54} \ldots \ldots \ldots \\
K_{2}=1.94 \times 10^{5} \ldots \ldots \ldots \ldots
\end{gathered}
$$

\subsection{The Calculation of the Grain Size in a Continuous Reheating Process}

Based on an isothermal model and on the rule of additivity (the heating cycle is subdivided into small successive isothermal time steps), Denis ${ }^{7)}$ developed a model for the analysis of the transformation kinetics during continuous cooling or heating.

Anelli $^{8}$ used this method for investigations of the grain growth during a continuous reheating process.

In the present paper, the Anelli method has been used to construct a model to predict the grain size in the austenite phase during a continuous heating process of a low carbon Si-Mn bearing TRIP steel.

The reheating curve was approximated by a series of isothermal steps in which every step has the same duration $\Delta t$ (see schematic representation in Fig. 1).

The grain growth occurring in the interval $\left(t_{i}, t_{i+1}\right)$ can be calculated in the following way:

i. the grain size $d_{i}$ obtained at a temperature $T_{i}$ after a continuous heating time $t_{i}$ is considered to be obtained through an isothermal soaking treatment at temperature $T_{i+1}$ during a fictitious time $t_{i+1}^{*}$. This time can be calculated by means of Eq. (8):

$$
t_{i+1}^{*}=\frac{d_{i}^{n}-d_{0}^{n}}{K_{1} \exp \left(K_{2} / T_{i+1}\right)}
$$

ii. after the time interval $\Delta t$, a grain size $d_{i+1}$ given by

$$
d_{i+1}=\left[d_{0}^{n}+K_{1}\left(t_{i+1}^{*}+\Delta t\right) \exp \left(K_{2} / T_{i+1}\right)\right]^{1 / n}
$$

is obtained.

The above explained procedure is schematically represented in Fig. 2. This figure contains a bundle of isothermal grain growth curves, corresponding to the different isothermal temperature steps considered.

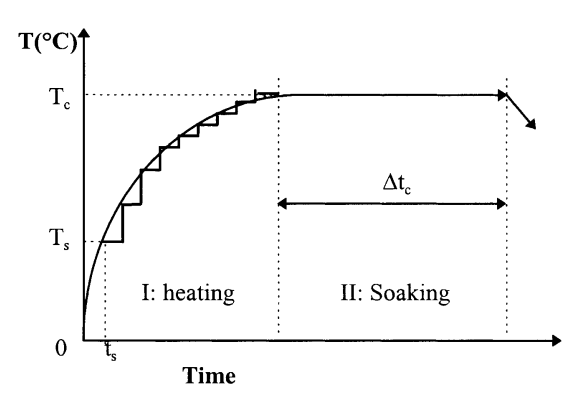

Fig. 1. A schematic temperature-time curve of the reheating of slabs in a reheating furnace. Approximation of the heating curve by a step function.

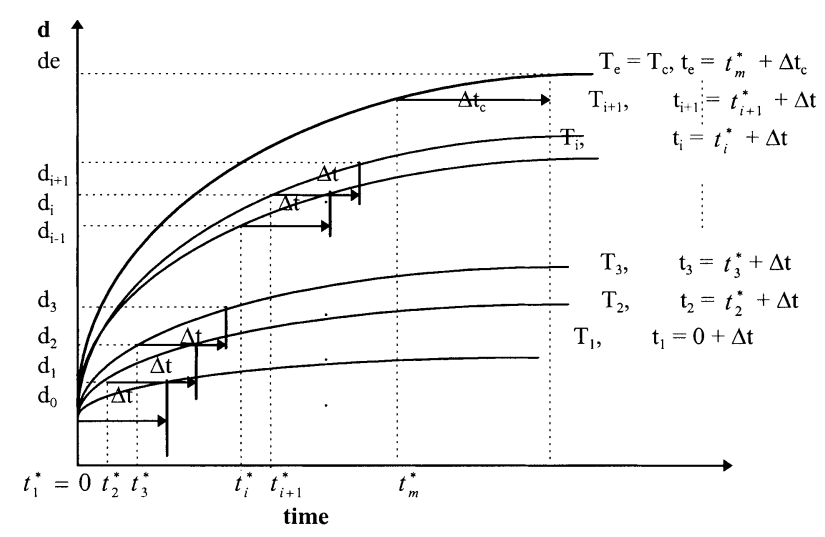

Fig. 2. Schematic illustration of Anelli's calculation procedure for the grain growth in a continuous reheating process.

Assuming the heating curve being represented by $T=f(t)$, the temperature corresponding to the $i$ th step can be calculated by means of formula (10):

$$
T_{i}=f\left(t_{\mathrm{s}}+i \cdot \Delta t\right)
$$

Since a model is constructed to predict the evolution of the austenite grain size during the last stage of a continuous heating process starting from low temperatures (e.g. room temperature), it has to be taken into account that a fully austenitic matrix is only attained at a temperature higher than the $\mathrm{Ac}_{3}$-temperature.

Defining this temperature as $T_{\mathrm{s}}$, the time $t_{\mathrm{s}}$ required to reach that temperature can be calculated by means of Eq. (11):

$$
t_{\mathrm{s}}=f^{-1}\left(T_{\mathrm{s}}\right)
$$

in which $f^{-1}$ stands for the inverse of the reheating function. If $t_{e}$ represents the time at which the heating is ended, the time intervals can be calculated by means of the formulae (12) or (13):

$$
\Delta t=\frac{t_{\mathrm{e}}-t_{\mathrm{s}}}{N}
$$

$$
\Delta t=\frac{f^{-1}\left(T_{\mathrm{e}}\right)-f^{-1}\left(T_{\mathrm{s}}\right)}{N}
$$

In both equations, $N$ represents an arbitrarily chosen integer bigger than 2 .

Figure 3 gives a flow chart of the calculation procedure. To start the calculations, $\Delta t$ can be arbitrarily set at a small 


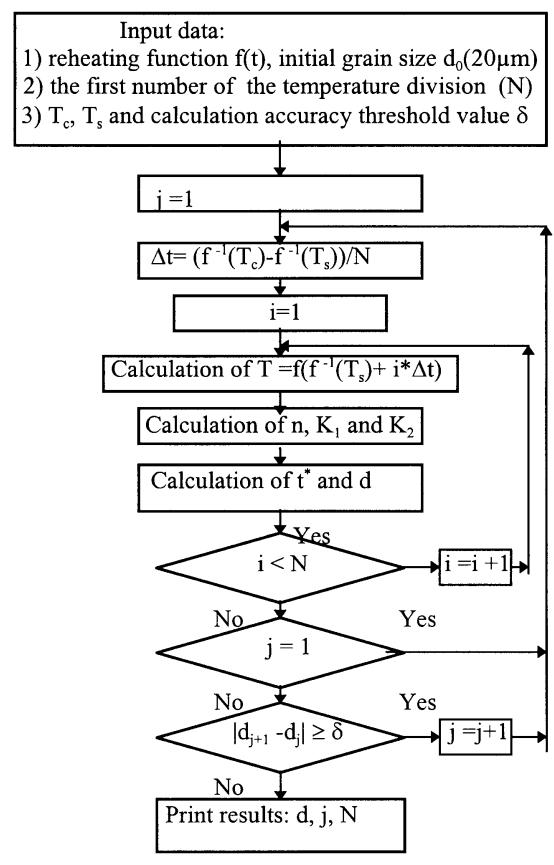

Fig. 3. Flow chart of the calculation procedure of the grain size in a continuous reheating process.

initial value, calculated by means of Eq. (12) or (13). For the next cycle, $\Delta t$ is reduced to $\Delta t / 2$ and so on. These iterations are stopped as soon as $\left[d_{\mathrm{e}}^{j+1}-d_{\mathrm{e}}^{j}\right] \leq \delta$ is satisfied. In this equation, $\delta$ is the threshold value with respect to the accuracy of the calculation. At the end of the calculation, the final grain size $d_{\mathrm{e}}$ is obtained.

Austenite grains are formed from the moment the $\mathrm{Ac}_{1}$ temperature is surpassed. Immediately after their formation these grains start growing. However, the grain growth occurring in the temperature range $\mathrm{Ac}_{1}-\mathrm{Ac}_{3}$ cannot be taken into account, since it is mainly due to the proceeding $\alpha \rightarrow \gamma$ transformation. This grain growth by interface movement has a totally different driving force than the one responsible for grain growth due to grain boundary movements. Therefore, the grain size obtained at a temperature of $960{ }^{\circ} \mathrm{C}$ was chosen to start the calculations. That temperature is a little bit higher than the experimentally determined $\mathrm{Ac}_{3}$ temperatures (see Table 1 and Fig. 4).

The model predicts a final grain size $d_{\mathrm{e}}$ after a reheating treatment. This predicted grain size can then be used as a starting grain size for the subsequent isothermal soaking.

It can thus be concluded that the combination of the continuous heating model and the isothermal one allows the modeling of classical reheating processes, consisting of a continuous heating followed by an isothermal soaking period.

\subsection{The Conversion of Grain Size from a Two Di- mensional (2-D) Space to a Three Dimensional (3- D) One}

The most commonly used method to determine the grain size of a material is the measurement of the linear intercept in a well defined plane (e.g. in a cross section, parallel to the rolling direction). However, a two dimensional (2-D) linear intercept does not always reflect the real grain size in a three dimensional (3-D) space. Therefore a good model should use the real grain size. So, the experimentally deter-
Table 1. The $\mathrm{Ac}_{1}$ and $\mathrm{Ac}_{3}$ temperatures of a low carbon $\mathrm{SiMn}$ TRIP steel for different heating rates.

\begin{tabular}{|c|c|c|}
\hline Heating rate $\left({ }^{\circ} \mathbf{C} / \mathbf{s}\right)$ & $\mathbf{A c}_{1}$ & $\mathbf{A c}_{3}$ \\
\hline 0.5 & 740 & 946 \\
\hline 1 & 746 & 950 \\
\hline 5 & 757 & 955 \\
\hline 10 & 773 & 958 \\
\hline
\end{tabular}

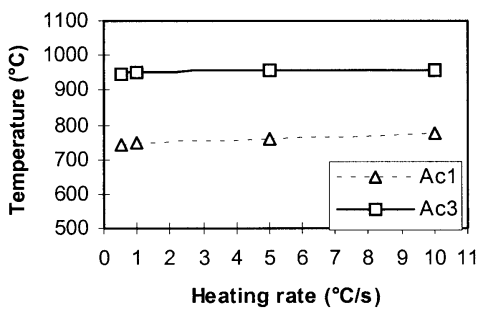

Fig. 4. Influence of the heating rate on the $\mathrm{Ac}_{1}$ and the $\mathrm{Ac}_{3}$ temperatures of a low carbon SiMn TRIP steel.

mined mean linear intercept distance has to be transformed into a mean real grain diameter. Takayama et al. ${ }^{9)}$ recently proposed a method to assess the spatial grain size from the linear intercept measurements, thereby assuming the spatial grain size distribution to be logarithmic normal and the grain shape being approximated by a tetrakaidecahedron. The logarithmic normal distribution function is presented in Eq. (14):

$$
f(d)=\frac{1}{\sqrt{2 \pi} d \ln s} \exp \left\{-\frac{\left[\ln \left(d / d_{g}\right)\right]^{2}}{2(\ln s)^{2}}\right\} \ldots \ldots \ldots
$$

It is characterised by the median grain diameter $d_{\mathrm{g}}$ and the standard deviation $s$. These parameters are related to the measured mean linear intercept $l_{\mathrm{m}}$ and mean area $A_{\mathrm{m}}$ through Eq. (15) and (16):

$$
\begin{gathered}
l_{\mathrm{m}}=0.60661 d_{\mathrm{g}} \exp \left(5(\ln s)^{2} / 2\right) \\
A_{\mathrm{m}}=0.4861 d_{\mathrm{g}}^{2} \exp \left(4(\ln s)^{2}\right) .
\end{gathered}
$$

Both equations allow to define the median grain diameter and the standard deviation as a function of $l_{\mathrm{m}}$ and $A_{\mathrm{m}}$ :

$$
\begin{aligned}
& d_{\mathrm{g}}=\left(\frac{0.60661}{l_{\mathrm{m}}}\right)^{4}\left(\frac{A_{\mathrm{m}}}{0.4861}\right)^{5 / 2} \\
& s=\exp \left(\left(\ln \left(1.321 \frac{l_{\mathrm{m}}^{2}}{A_{\mathrm{m}}}\right)\right)^{1 / 2}\right)
\end{aligned}
$$

Furthermore, the median grain diameter and the mean one are connected to each other by Eq. (17):

$$
d_{\mathrm{m}}=d_{\mathrm{g}} \exp \left((\ln s)^{2} / 2\right) \text {. }
$$

\section{Experimental Procedure}

In order to verify the heating model and to study the effect of the heating rate on the prediction accuracy, two series of experiments were set up:

i. a continuous heating to different intermediate temperatures. 
ii. heating to the same temperature with different constant rates.

\subsection{Material}

The low carbon, Si-Mn TRIP steel used for this investigation had the following chemical composition (mass\%): $0.112 \mathrm{C}, 1.26 \mathrm{Si}, 1.53 \mathrm{Mn}, 0.0135 \mathrm{P}, 0.0075 \mathrm{~S}, 0.029 \mathrm{Al}_{\text {tot }}$, $0.0017 \mathrm{~N}, 0.021 \mathrm{Cr}$ and $0.022 \mathrm{Ni}$.

It was produced under a protective argon atmosphere in a vacuum melting and casting unit and cast as an ingot of approximately $100 \mathrm{~kg}$.

The different samples required for this investigation have all been taken from the as cast ingot.

\subsection{Experimental Facilities}

Two different apparatus were used to perform the heat treatments required:

i. a Theta dilatometer equipped with quenching and deformation facilities. The specimens are heated under vacuum (maximum $10^{-4} \mathrm{~Pa}$ ), while the quenching occurs by means of a helium jet. The maximum heating and cooling rates attainable are respectively $150^{\circ} \mathrm{C} / \mathrm{s}$ and $100^{\circ} \mathrm{C} / \mathrm{s}$ for massive cylindrical specimens of $\phi 3.5$ $\mathrm{mm} \times 5 \mathrm{~mm}$. The temperature variation and the dilatation of the sample are simultaneously recorded on a paper chart and introduced into a computer.

ii. a program controlled electric resistance furnace allowing a maximum working temperature of $1300^{\circ} \mathrm{C}$ and a maximum heating rate of $0.5^{\circ} \mathrm{C} / \mathrm{s}$.

\subsection{Specimens}

For the dilatometer, massive cylindrical specimens with a diameter of $3.5 \mathrm{~mm}$ and a height of $5 \mathrm{~mm}$ have been used.

On the contrary, for the resistance furnace prismatic specimens of $20 \mathrm{~mm} \times 10 \mathrm{~mm} \times 5 \mathrm{~mm}$ have been used.

\subsection{The Etching of the Prior Austenite Grain Bound- aries}

The heat treated samples have been quenched into water in order to obtain a martensitic structure. Afterwards, they have been tempered for $13 \mathrm{hr}$ at $350^{\circ} \mathrm{C}$, in order to improve their etching behavior. ${ }^{5}$ ) After this tempering treatment, the samples are etched in an aqueous solution of oxalic acid and hydrogen peroxide. The details of the etching procedure are summarized in Table 2.

\subsection{Heat Treatments}

For the experiments to investigate the prediction accuracy of the model at different intermediate temperatures, an electrical resistance furnace was used. At the moment the required temperature was obtained, the sample was quenched into water (see schematic representation of the heating cycle applied in Fig. 5).

For the experiments to investigate the effect of different heating rates on the prediction accuracy of the model, the dilatometer was used for the reheating rates of $1^{\circ} \mathrm{C} / \mathrm{s}$ and of $0.5^{\circ} \mathrm{C} / \mathrm{s}$. The electric resistance furnace was used for the reheating rate of $0.1^{\circ} \mathrm{C} / \mathrm{s}$. At the end of each test, the dilatometer samples were quenched into a helium jet while the other ones were quenched into water. Figure 6 gives a schematic representation of these reheating cycles.
Table 2. Parameters for the revelation of the prior austenite grain boundary of a low carbon SiMn TRIP steel.

\begin{tabular}{|l|l|}
\multicolumn{1}{c|}{ TRIP steel } \\
\hline Tempering treatment: & 13 hours at $350{ }^{\circ} \mathrm{C}$ \\
\hline Recipe of the etchant: & $\begin{array}{l}\text { Water: } 80 \mathrm{ml} \\
\text { Oxalic acid }(10 \%): 28 \mathrm{ml} \\
\mathrm{H}_{2} \mathrm{O}_{2}(30 \%): 4 \mathrm{ml}\end{array}$ \\
\hline Etching parameters: & $\begin{array}{l}\text { Time: } 0.5-21 \mathrm{~min} . \\
\text { Temperature: } 20{ }^{\circ} \mathrm{C}\end{array}$ \\
\hline
\end{tabular}

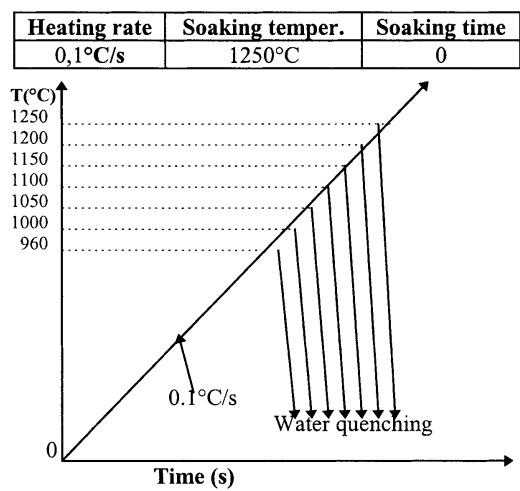

Fig. 5. Test cycle to investigate the grain growth in a continuous reheating process.

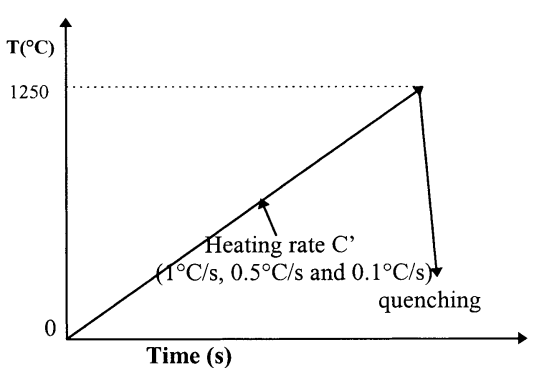

Fig. 6. Test cycle to investigate the grain growth in a continuous reheating process with different heating rates.

\section{Results}

\subsection{Grain Growth in a Continuous Heating Process with a Heating Rate of $0.1^{\circ} \mathrm{C} / \mathrm{s}$}

The micrographs of the samples after continuous heating at different temperatures with a rate of $0.1^{\circ} \mathrm{C} / \mathrm{s}$ are shown in Fig. 7. The measured mean linear intercept and the calculated real grain size are shown in Fig. 8.

In Fig. 9, the predicted 3-D grain diameter is compared with the experimentally determined 3-D diameter. This figure also contains the error on these calculations.

That error being situated between 10 and $16 \%$, indicates that the predictive model is quite acceptable.

\subsection{Grain Growth in Continuous Heating Processes with Three Different Heating Rates}

The micrographs of the samples tested at $1250^{\circ} \mathrm{C}$ after a continuous reheating process with three different heating rates are shown in Fig. 10.

It can be concluded that a higher heating rate leads to a finer austenitic grain size, which is in fact normal since a slower heating rate gives the austenite grains larger opportunities to grow.

In Fig. 11, the calculated mean 3-D diameter is com- 
a) $960^{\circ} \mathrm{C}$

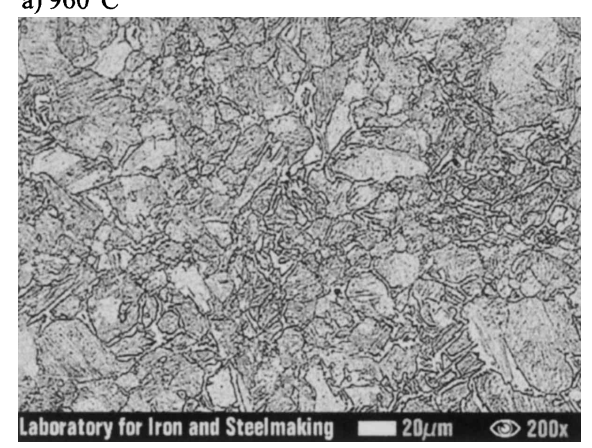

c) $1050^{\circ} \mathrm{C}$

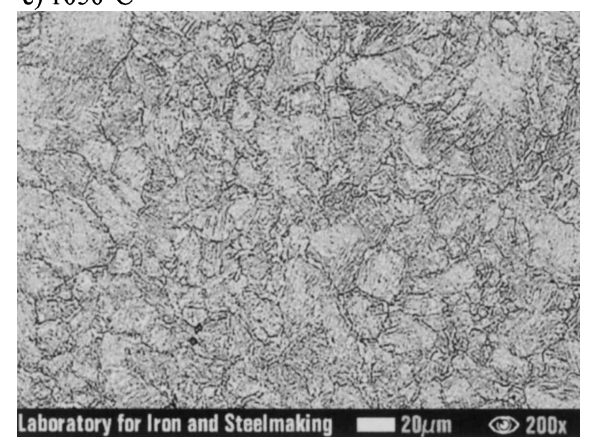

e) $1150^{\circ} \mathrm{C}$
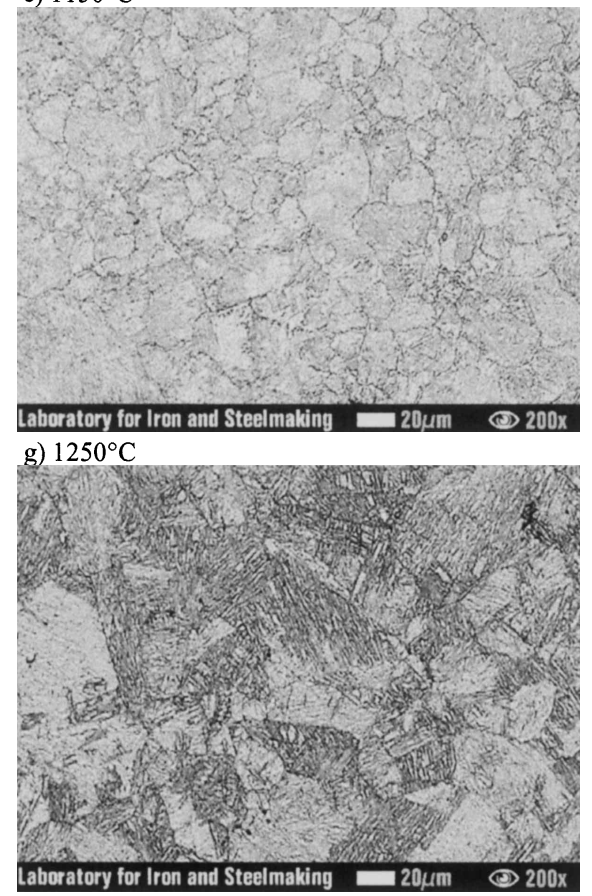

Fig. 7. Grain size at different temperatures in a continuous reheating process with a heating rate of $0.1^{\circ} \mathrm{C} / \mathrm{s}$.

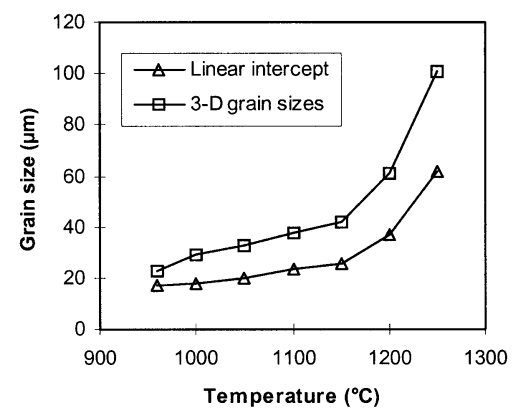

Fig. 8. Mean linear intercepts together with the converted 3-D grain diameter in a continuous heating process with a heating rate of $0.1^{\circ} \mathrm{C} / \mathrm{s}$. b) $1000^{\circ} \mathrm{C}$

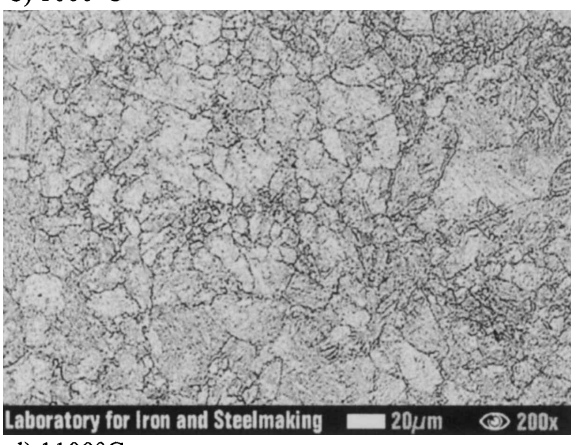

d) $1100^{\circ} \mathrm{C}$

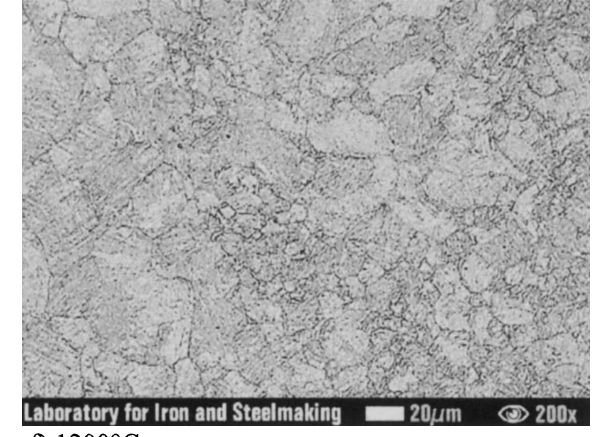

f) $1200^{\circ} \mathrm{C}$

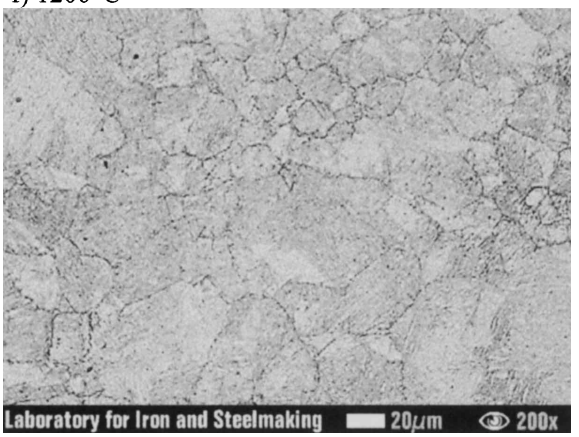




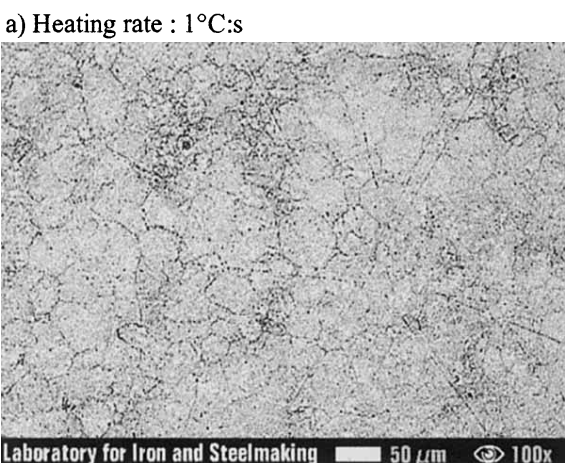

b) Heating rate $: 0.5^{\circ} \mathrm{C}: \mathrm{s}$
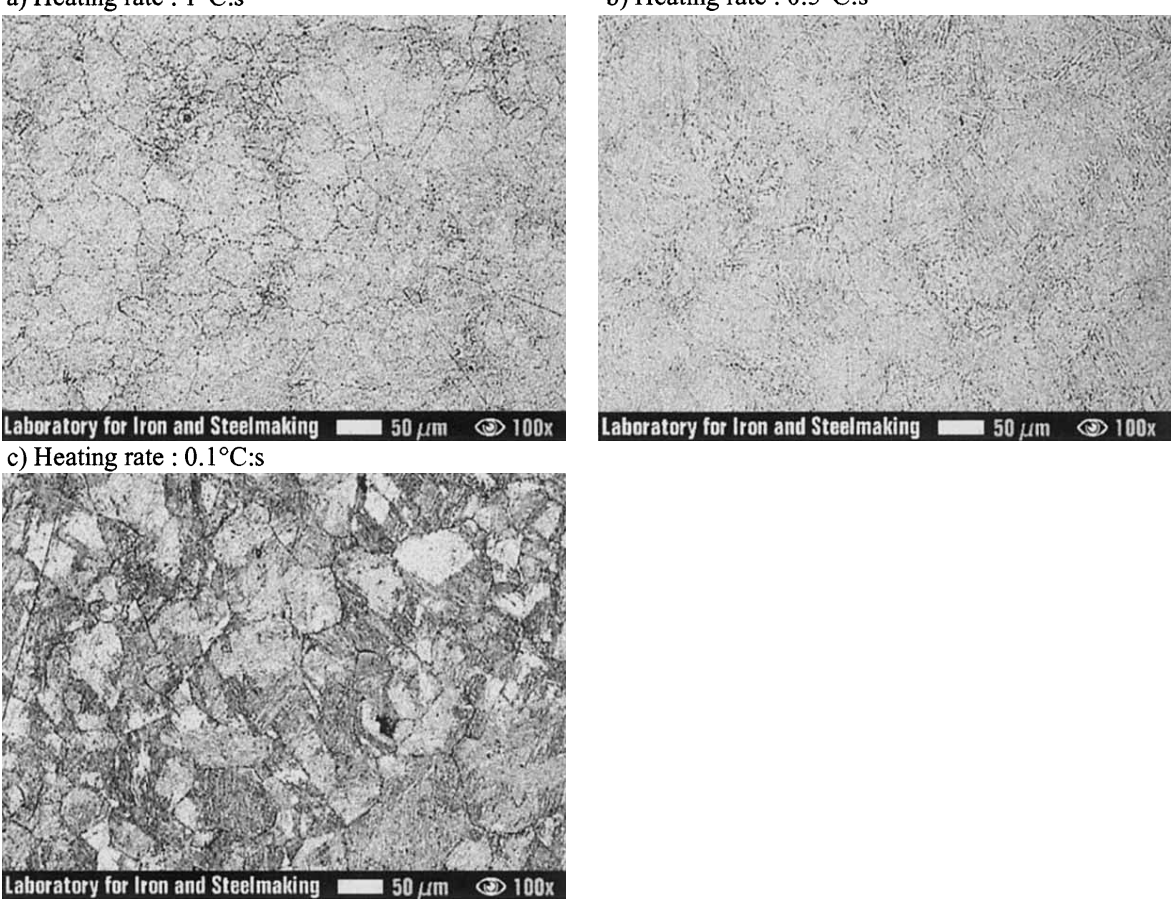

Fig. 10. Effect of the heating rate on the grain growth.

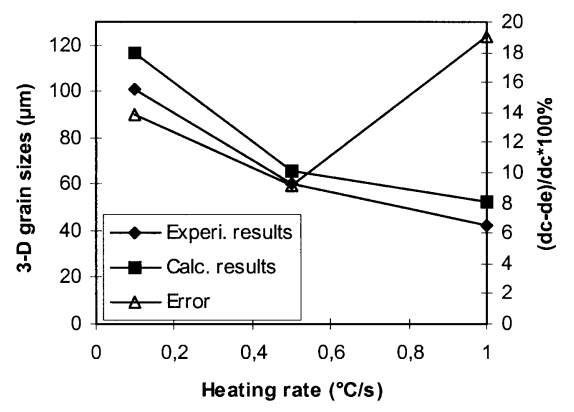

Fig. 11. Comparison between the measured 3-D grain size and calculated one in a continuous heating process for three different heating rates.

pared with the measured one. This figure also contains the error on the calculated values. These errors are situated between 9 and $19 \%$, which again can be considered as reasonable.

\section{Conclusions}

(1) Making use of Anelli's idea and an adapted model for isothermal austenitic grain growth, a model for the austenite grain growth during a continuous heating process was developed.

(2) The model has been constructed using the real three dimensional grain size. There are considerable differences between this diameter and the experimentally determined linear intercept distance. This means that linear intercept distances cannot be used in the model developed.

(3) The comparison of the measured real grain diameter and the calculated one in a continuous process with different finishing temperatures $\left(960\right.$ to $\left.1250^{\circ} \mathrm{C}\right)$ and different heating rates $\left(0.1,0.5\right.$ and $\left.1{ }^{\circ} \mathrm{C} / \mathrm{s}\right)$, showed that the grain size can be predicted with an error between 10 and $20 \%$, which seems quite acceptable.

\section{Acknowledgements}

The authors gratefully acknowledge the financial support from the Belgian State: Prime Minister's Office: Federal Office for Scientific, Technical and Cultural Affairs (Interuniversity Poles of Attraction Program), under contract $\mathrm{P} 4 / 33$.

The authors wish to thank Dr. L. Kestens for helpful discussions.

\section{REFERENCES}

1) M. Sellars: Proc. Thermo-Mechanical Processing in Theory, Modelling \& Practice, ed. by Swedish Society for Materials Technologies, Stockholm, (1997), 35.

2) J. Jonas: Iron Steelmaker, 10 (1992), 67.

3) P. Sun, M. Militzer, E. B. Hawbolt and J. J. Jonas: Iron Steelmaker, 5 (1998), 85 .

4) O. Kwon: ISIJ Int., 32 (1992), 350.

5) S. Jiao, J. Penning, F. Leysen and Y. Houbaert: Steel Res., in press.

6) S. Jiao, J. Penning, F. Leysen and Y. Houbaert: Steel Res., in press.

7) S. Denis: ISIJ Int., 32 (1992), 316.

8) E. Anelli: ISIJ Int., 32 (1992), 440.

9) Takayama, N. Furushio and T. Tozawa: Mater. Trans. JIM, 32 (1991), 214. 